\title{
Fórum pela Vida \\ Plantas Medicinais e Mobilização Social no Noroeste Gaúcho
}

http://dx.doi.org/10.21527/2237-6453.2019.47.265-282

Recebido em: $13 / 3 / 2018$

Aceito em: $18 / 12 / 2018$

\author{
Flávia Charão Marques ${ }^{1}$, Tamara Raísa Bubanz Silva²
}

\begin{abstract}
RESUMO
Este artigo apresenta a identificação das dinâmicas dos atores sociais relacionadas à temática das plantas medicinais na Região Noroeste do Rio Grande do Sul, por meio da experiência do Fórum pela Vida. O estudo justifica-se pelas contribuições que pode dar às discussões sobre desenvolvimento, demonstrando a heterogeneidade do rural e a valorização dos conhecimentos tradicionais. Trata-se de uma pesquisa qualitativa que utilizou a Perspectiva Orientada aos Atores (POA) como ferramenta teórica e metodológica. A coleta de dados ocorreu de março a junho de 2015, mediante entrevista semiestruturada, observação e análise dos dados e de conteúdo. Constatou-se que, ao seguir as práticas sociais, as experiências e os mundos de vida dos atores evidenciam as formas heterogêneas no rural, possibilitando repensar os processos de desenvolvimento, uma vez que os atores sociais possuem agência e realizam manobras para garantir seus mundos de vida. Pela ação social, ademais, buscou-se a construção de políticas públicas voltadas ao reconhecimento das práticas e saberes populares e ressaltou-se a ação social e a luta pelo resgate do conhecimento sobre as plantas medicinais.
\end{abstract}

Palavras-chave: Ação social. Plantas medicinais. Mulheres rurais.

\section{FORUM FOR LIFE: MEDICINAL PLANTS AND SOCIAL MOBILIZATION IN THE NORTHWEST GAUCHO}

\section{ABSTRACT}

This article presents the identification of the dynamics of social actors related to the theme of medicinal plants in the Northwest region of Rio Grande do Sul, through the experience of the Forum for Life. The study is justified by the contributions it can make to the discussions on development, demonstrating the heterogeneity of the rural and the valuation of traditional knowledge. It is a qualitative research that used the Oriented Perspective to Actors (POA) as a theoretical and methodological tool. Data collection took place from March to June 2015, through a semi-structured interview, observation and analysis of data and content. It was verified that, in following the social practices, the experiences and the worlds of life of the actors show the heterogeneous forms in the rural, making possible to rethink the development processes, once the social actors have agency and they realize maneuvers to guarantee their worlds of life. Through social action, in addition, we sought the construction of public policies aimed at the recognition of popular practices and knowledge and emphasized social action and the struggle to rescue knowledge about medicinal plants.

Keywords: Social action. Medicinal plants. Rural women.

\footnotetext{
${ }^{1}$ Doutora em Desenvolvimento Rural pela Universidade Federal do Rio Grande do Sul (UFRGS). Professora da Universidade Federal do Rio Grande do Sul (UFRGS). flavia.marques@ufrgs.br

${ }^{2}$ Mestre em Desenvolvimento Rural pela Universidade Federal do Rio Grande do Sul. Aluna de Doutorado no Programa de Pós-Graduação em Desenvolvimento Rural da Universidade Federal do Rio Grande do Sul. tamara.bubanz@gmail.com
} 
Este artigo propõe identificar dinâmicas sociopolíticas dos atores sociais relacionadas à temática das plantas medicinais no contexto da Região Noroeste do Rio Grande do Sul. Essa região é marcada - é importante salientar - por um passado de intensa presença indígena e pelas disputas do território com imigrantes alemães, russos, italianos, poloneses, dentre outros, no processo de criação das colônias. Outro aspecto a se destacar é o de que esses encontros de diferentes povos foram moldando identidades e mesclando conhecimentos acerca da utilização das plantas medicinais que não desapareceram ao longo do tempo, ainda que o processo de modernização da agricultura tenha imprimido mudanças profundas no território.

As plantas com propriedades medicinais sempre estiveram presentes na vida das famílias e comunidades, com seus usos constituindo, muitas vezes, a principal estratégia de cuidado da saúde. Se, no entanto, por um lado o estigma do atraso atribuído ao uso de formas ancestrais de conhecimento ocasionou a perda de muitas práticas e conhecimentos, por outro, os repertórios culturais e a tradicionalidade relacionados estimulam as pessoas a seguir fazendo uso das plantas e outras práticas populares em saúde até os dias atuais.

As práticas relacionadas à saúde humana, animal e ambiental, dentre elas o uso de plantas, estão imbricadas com a vida cotidiana, não se restringindo somente ao uso medicinal pela população urbana e rural, mas por relações mais complexas. Por exemplo, envolvem aspectos de utilização alimentar e práticas ritualísticas diversas, também associadas à espiritualidade. Dessa forma, tais práticas mobilizam conhecimentos e tradicionalidade, fazendo parte do que se pode identificar como heterogeneidades emergentes, considerando que - mesmo existindo intervenções modernizantes que interferem nos modos de vida dos indivíduos e dos grupos sociais - elas são mediadas e transformadas pela agência desses mesmos indivíduos (LONG, 2001, 2007; LONG; PLOEG, 1994). Em outras palavras, neste trabalho o uso das plantas medicinais é tratado no conjunto das críticas endereçadas ao desenvolvimento como processo homogeneizante e unicamente legitimado pela ciência moderna.

No Noroeste do Rio Grande do Sul, como em outras regiões do Brasil, o modelo de desenvolvimento, focado na modernização da agricultura - de acordo com Benetti (2002) -, consolida-se na década de 90 do século 20 e acaba por dar protagonismo às indústrias com participação do capital internacional. Um argumento central, no entanto, é que, a despeito das tentativas homogeneizadoras e da globalização que, aparentemente, centralizam o desenvolvimento, um olhar apurado vai mostrar uma série de outros processos emergentes.

A modernização sempre se opôs à tradição, uma vez que, conforme Giddens (1997, p. 73), "[...] a modernidade reconstruiu a tradição enquanto a dissolvia". A tradição, todavia, não é algo estático, pois ela sofre mudanças ao longo dos tempos e, assim, pressupõe-se a sua persistência. Segundo Giddens (1997), ela se desenvolve e amadurece ou enfraquece e morre, compreendendo o processo contínuo de conexão com passado e presente. Em vista disso, na medida em que os atores sociais mobilizam processos de reconstrução e manutenção da tradição, eles transformam atividades humanas, resolvendo os problemas, aprendendo como intervir no fluxo de eventos sociais e monitorando suas próprias ações. 
Até mesmo em locais em que o processo de desenvolvimento foi profundamente influenciado pela modernização - como é o caso da Região Noroeste - a tradicionalidade no uso das plantas medicinais, que vinha desde períodos anteriores, mantém-se, não como algo relacionado a um passado estático, mas como parte das dinâmicas de transformação vividas pelas pessoas. Assim, a defesa do uso das plantas medicinais como um recurso terapêutico legítimo acaba por constituir uma série de mobilizações associadas à luta política pela valorização e reconhecimento dessa forma de conhecimento. Como foco em processos ocorridos no Rio Grande do Sul desde a metade dos anos 90, o artigo está baseado em pesquisa sobre o Fórum pela Vida, que pode ser identificado como uma série de eventos de celebração e compartilhamento do conhecimento, bem como do fortalecimento das experiências de trabalho com plantas medicinais.

O Fórum pela Vida descende de uma organização política estadual iniciada no ano de 1998, a qual foi coordenada pela Comissão de Saúde e Meio Ambiente da Assembleia Legislativa do Rio Grande do Sul, estando presente em todas as regiões do Estado. A partir do Projeto Plantas Vivas - que buscava reunir esforços para construir uma política de assistência farmacêutica no intuito de unificar os saberes científico e popular pela valorização das plantas medicinais nativas - inicia-se a mobilização de diversas organizações sociais (por exemplo movimentos pró-saúde pública, organizações religiosas, sindicatos urbanos e rurais, movimentos sociais, instituições de ensino e pesquisa). O projeto resultou em uma política estadual pioneira e se desdobrou em inúmeras iniciativas; porém, ao longo dos anos, sofreu com a desmobilização em grande parte das regiões do RS. Aqui, o destaque está para o processo no Noroeste gaúcho, onde o Fórum pela Vida acabou por desencadear uma dinâmica organizativa própria e, com o tempo, ampliou debates e conhecimentos sobre plantas medicinais.

Tendo como base teórico-metodológica a Perspectiva Orientada ao Ator (LONG, 2001; ARCE; LONG, 1994), este artigo identifica atores sociais locais que estão envolvidos no trabalho com plantas medicinais, evidenciando experiências e iniciativas que fazem parte da mobilização que desencadeia o Fórum pela Vida no Noroeste do RS. Além disso, descreve a ação estadual do Projeto Plantas Vivas, de modo a analisar sua influência na criação de espaços regionais de articulação política, inicialmente na região Fronteira Noroeste e, mais tarde, na região das Missões.

O presente artigo encontra-se estruturado em cinco seções, incluindo esta introdução. Na segunda seção é apresentado o percurso metodológico para o desenvolvimento da pesquisa. Em seguida, o Projeto Plantas Vivas é descrito, colocando em evidência o grande contingente de pessoas interessadas ou envolvidas com as temáticas das plantas medicinais, saúde, produção de medicamentos, políticas públicas, proteção da biodiversidade, dentre outras. Na quarta seção é abordado o Fórum pela Vida na Região Noroeste, com a identificação dos atores sociais e da dinâmica organizativa, transversalidade de temas e interfaces de conhecimentos apresentados no contexto local. Por fim, nas Considerações Finais, são trazidos alguns aspectos que se destacam a partir da análise empreendida, seguida das referências bibliográficas empregadas no estudo. 


\section{METODOLOGIA}

Com base em uma abordagem qualitativa, este estudo ${ }^{3}$ foi desenvolvido e realizado na Região Noroeste do Rio Grande do Sul, mais precisamente nas Regiões Fronteira Noroeste e Missões, entre os anos de 2015 e 2016, de acordo com a definição do Conselho Regional de Desenvolvimento (Corede). Foram entrevistadas 16 pessoas participantes do Fórum pela Vida. As entrevistas foram direcionadas a informantes-chave identificados como parte dos principais grupos envolvidos na organização do Fórum, sendo extensionistas da Emater-RS, ${ }^{4}$ agentes de saúde, participantes da Pastoral da Saúde (Igreja Católica), integrantes do Sindicato dos Trabalhadores Rurais, de cooperativa regional e do movimento de mulheres, no período de março a junho de 2015, com utilização de entrevistas semiestruturadas. Foi realizado acompanhamento semanal das atividades relacionadas à organização do Fórum, conforme a disponibilidade dos informantes, em cujos momentos as atividades foram diretamente observadas e as entrevistas puderam ser aprofundadas. Além disso, de forma complementar, foram utilizados não apenas registros fotográficos, análise das atas e memórias de reuniões e relatórios do Fórum pela Vida disponibilizados pelos entrevistados, mas também materiais como fotografias e programações dos encontros.

Fundamentalmente, a estratégia metodológica foi seguir as práticas sociais, que, além de oferecerem pistas sobre os processos de construção e reconstrução social, permitiram evidenciar as interações que emergem na ação local sem perder a dimensão da influência, tanto dos contextos mais amplos quanto das possíveis continuidades e descontinuidades sociais (LONG, 2001).

Nesse sentido, foram considerados os atores sociais em sua capacidade de processar a experiência social e mobilizar distintas maneiras de lidar com a vida, especialmente pela "capacidade de saber" e "capacidade de atuar" ante os problemas (LONG, 2007). Sendo assim, a observação das práticas sociais envolveu o registro de elemento, aspectos e fatos ligados às relações sociais, mobilizações, processos de organização e manipulação de recursos materiais.

Os atores sociais são todos os indivíduos e entidades sociais que possuem a capacidade de conhecer e avaliar situações problemáticas e, a partir delas, organizar respostas. Podem ser pessoas individuais, grupos, redes, organizações ou até mesmo governos, igreja ou organizações internacionais (LONG, 2007).

A pesquisa de campo permitiu o exame aprofundado das qualidades do fenômeno em foco, possibilitando identificar e compreender dimensões subjetivas da ação humana, como sugerem Brumer et al. (2008), ao circunscreverem a abordagem qualitativa. Com isso, a análise dos dados gerados nas entrevistas, notas de campo, documentos, áudios e fotografias favoreceu um processo de interpretação, organizando as informa-

\footnotetext{
${ }^{3}$ Os dados apresentados neste trabalho fazem parte de dissertação de Mestrado defendida pela segunda autora, em 2016, junto ao Programa de Pós-Graduação em Desenvolvimento Rural (PGDR) na Universidade Federal do Rio Grande do Sul (UFRGS).

${ }^{4}$ Organização de extensão rural, presente em quase todos os municípios do RS.
} 
ções em virtude de sua relevância para a reconstituição do histórico das organizações, da atuação das pessoas envolvidas no Fórum pela Vida, além da sistematização de temas abordados ao longo dos anos de realização do evento.

\section{RESULTADOS E DISCUSSÕES}

A presente seção discute os principais resultados da pesquisa. Para uma melhor compreensão, está subdividida em duas partes: a primeira trata sobre a construção do Fórum pela Vida, que perpassa desde a sua criação, a partir de uma ação estadual do Projeto Plantas Vivas desenvolvido, inicialmente, pela Assembleia Legislativa; na segunda seção será apresentada a dinâmica do Fórum pela Vida na Região Noroeste e a transversalidade de temas e interfaces de conhecimentos apresentados no contexto local, uma vez que a ação social se desprendeu do projeto estadual e criou meios para dar continuidade ao trabalho localmente em razão da interrupção dos trabalhos em âmbito estadual.

\section{A CONSTRUÇÃO DO FÓRUM PELA VIDA: Uma Ação Estadual}

O Fórum pela Vida na Região Noroeste é um processo organizativo local/regional que deriva de outros processos mais amplos que tiveram, por certo período, abrangência estadual e que, de certa forma, contribuíram para a criação de políticas públicas tanto estadual quanto nacional. Deste modo, não há como delinear sua trajetória sem antes trazer alguns aspectos, em especial do Projeto Plantas Vivas, desenvolvido com apoio da Assembleia Legislativa do Rio Grande do Sul e que mobilizou grande contingente de pessoas interessadas ou envolvidas com as temáticas das plantas medicinais, saúde, produção de medicamentos, políticas públicas, proteção da biodiversidade, dentre outras.

O início da organização social se deve à relação entre plantas medicinais e reivindicações por melhores condições de vida e de saúde, principalmente da população rural, uma relação que não é recente. Tomado este elemento, pode-se destacar que uma das primeiras ações com abrangência estadual organizada no RS foi a criação da Comissão Estadual sobre Plantas Medicinais, um grupo de caráter interinstitucional e multidisciplinar formalizado durante o Primeiro Encontro Estadual sobre Plantas Medicinais, ocorrido em 1994, e que teria precedido e influenciado a criação do Fórum pela Vida (CHARÃO-MARQUES, 2009).

Já em 1998 foi estabelecido o Projeto Plantas Vivas que daria origem ao Fórum pela Vida, abrigado pela Comissão de Saúde e Meio Ambiente da Assembleia Legislativa, porém contando com amplo envolvimento popular e de organizações governamentais e não governamentais. O Primeiro Seminário Plantas Vivas ocorreu em julho de 1998, resultando em um documento compromisso chamado de "Carta de Porto Alegre - Plantas Vivas para uma Sociedade Viva". Os participantes signatários eram de órgãos públicos do Poder Executivo, instituições de pesquisa, universidades, organizações populares, sindicatos, profissionais de diversas áreas e outras organizações. Na carta faz-se um apelo para que haja uma valorização e produção de medicamentos fitoterápicos por parte do Estado. Esse primeiro seminário marca o início da trajetória do Projeto Plantas Vivas, que buscava a criação de uma cadeia produtiva de fitoterápicos pelo estabeleci- 
mento de polos regionais que contemplassem ações coordenadas e infraestrutura de produção de plantas medicinais e demais matérias-primas destinadas para a produção de fitoterápicos.

Logo que foi lançado o Projeto Plantas Vivas, o Fórum pela Vida foi criado com a estratégia de responder ao objetivo estabelecido na Carta de Porto Alegre: "promover a integração entre os saberes popular e científico (tradicional e acadêmico) para que o uso das plantas medicinais seja universalizado, com eficácia, segurança e qualidade? (CONY, 2004, p. 10). O Fórum pela Vida estava organizado, inicialmente, em sete regionais, que correspondiam à divisão organizativa da Secretaria Estadual de Saúde: Vales, Sul, Centro-Oeste, Norte, Serra, Missioneira e Metropolitana.

No ano seguinte, em 1999, foi publicado o primeiro livreto ${ }^{5}$ contendo a memória das discussões realizadas no primeiro seminário e trazendo uma síntese das palestras e deliberações, o que se sucedeu nos demais eventos. Inicialmente as regiões Fronteira Noroeste e Missões não faziam parte do Fórum pela Vida, sendo a regional Missioneira a mais próxima, que tinha como referência a cidade de ljuí. Somente mais tarde as regiões integrariam o FPV, formando um núcleo próprio, pois, apesar de serem próximas geograficamente, possuem trajetórias diferenciadas, demonstrando um pouco da heterogeneidade nos contextos locais.

Cabe mencionar que no ano de 1999, quando foram realizados os primeiros encontros nas regionais do FPV, foram reunidas 1.402 pessoas no total, que, com o passar dos anos, ampliou-se devido à criação de mais núcleos regionais. Uma das regiões onde houve a maior participação dos atores locais foi a Missioneira, com 298 participantes, demonstrando, desde o início, o interesse despertado pela temática das plantas medicinais e políticas públicas.

A partir dos encontros regionais do FPV foram elaborados relatórios contendo diversas propostas para o cumprimento das metas definidas, sendo discutidas no 2ㅇ Seminário Estadual do Projeto Plantas Vivas, realizado no final de 1999. As contribuições resultaram numa sistematização das propostas que abordaram temas como cooperativismo, agricultura, ensino e legislações. Também foram encaminhadas propostas destinadas à União, Estado e municípios, especialmente visando a ações integradas para incentivar a pesquisa, financiamento, formação de recursos humanos, projetos piloto de agroindústrias em Plantas Medicinais, etc. (CONY, 2004).

Após a sistematização, algumas ações foram realizadas para dar seguimento às metas definidas nos Fóruns regionais. Talvez a mais significativa tenha sido a solicitação para que o governo estadual criasse uma Comissão Intersecretarial de Plantas Medicinais de modo a encaminhar e coordenar o debate para o estabelecimento de uma Política Estadual de Plantas Medicinais e Medicamentos Fitoterápicos. Em resposta a essas reivindicações, o governo estadual da época institucionalizou, em 2000, tal comissão. Durante a realização do 30 Seminário Estadual, em 2001, o governo estadual apresentou o projeto para criar a Política Intersetorial de Plantas Medicinais.

\footnotetext{
Este material e outros que se sucederam foram publicados com recursos da Assembleia Legislativa, via cota orçamentária da Comissão de Saúde e Meio Ambiente e, mais tarde, do gabinete da deputada estadual Jussara Cony, também coordenadora geral do Fórum pela Vida.
} 
Estes são desdobramentos importantes da mobilização estimulada pelo Fórum, sem, todavia, desconsiderar que foram muitas as pessoas e organizações que fizeram o debate e as pressões políticas para que a Política Intersetorial de Plantas Medicinais fosse desenhada. Outro exemplo de desdobramento das articulações promovidas no âmbito do Fórum são parcerias estabelecidas para realizar cursos de qualificação no Programa Qualificar-RS, realizadas a partir de 2000, e que tinham como tema as plantas medicinais, aromáticas e condimentares. Os cursos eram destinados à capacitação de gestores públicos e agricultores familiares. O esforço multi-institucional envolveu o Ministério do Trabalho e Emprego, a Secretaria de Trabalho, Cidadania e Assistência Social, a Secretaria da Agricultura e Abastecimento, a Emater/RS e a UFRGS.

Ainda, durante a realização do terceiro seminário foram criadas mais duas regionais que passaram a integrar o Fórum pela Vida - Campanha e Noroeste (chamada inicialmente de Grande Santa Rosa) -, totalizando, assim, nove regionais. Em cada seminário estadual novas contribuições e propostas chegavam da ação coletiva dos fóruns com o objetivo de fomentar o cultivo e uso das plantas medicinais. Uma das conquistas foi à aprovação da Lei Estadual 11.858/2002, que institui a "marcela" (Achyrocline satureioides) como planta medicinal símbolo do Rio Grande do Sul, por se tratar de uma espécie nativa de uso medicinal e religioso. Este tipo de desdobramento das ações acaba por dar mais visibilidade para os debates e, assim, chamar atenção para os temas e estimular a participação.

Em paralelo às ações do Projeto Plantas Vivas, foi criada a Rede de Implementação da Cadeia Produtiva de Fitoterápicos (Rede Fito/RS), no ano de 2001, uma articulação entre o governo estadual, universidades, centros de pesquisa, agricultores e empresas, para promover e fortalecer a base tecnológica local para a cadeia produtiva de medicamentos fitoterápicos. Dentre os objetivos da Rede Fito/RS, constava criar a base tecnológica necessária ao segmento farmacêutico; intensificar a relação do poder público com as universidades e empresas; contribuir com a disponibilização de medicamentos fitoterápicos para o SUS; aproximar as empresas farmacêuticas gaúchas dos centros de pesquisa locais e das agências de fomento visando a sua adequação à legislação e modernização tecnológica; dotar os centros de pesquisa gaúcho de condições de cooperação técnica com a indústria local e ampliar as possibilidades de mercado para as empresas farmacêuticas gaúchas (SECRETARIA..., 2012).

As ações da Rede Fito/RS mobilizaram diversos atores desde agricultores familiares até a indústria para a realização de diversas atividades, como reuniões, seminários, visitas técnicas, eventos de capacitação, dentre outros. O desafio de estabelecer a cadeia produtiva, porém, estava distante de se concretizar, pois a iniciativa necessitava de recursos financeiros para ser efetivada. Assim, a Rede Fito/RS, com o passar dos anos, foi perdendo o apoio político por parte do governo estadual, seu principal gestor, persistindo somente até 2006.

Uma das ações iniciadas pela Rede Fito/RS e que gerou desdobramentos interessantes, foi um projeto de apoio a iniciativas que envolviam a geração de conhecimento pela integração e participação dos atores envolvidos na produção e processamento de plantas medicinais, como agricultores, extensionistas, pesquisadores, gestores, dentre outros. O projeto angariou apoio do Fundo Internacional para o Desenvolvimento da Agricultura (Fida), órgão vinculado à Organização das Nações Unidas (ONU), passando, 
posteriormente, à gestão para a esfera federal. Assim, em 2003 o projeto original é ampliado e é lançado o Programa de Plantas Medicinais do Mercosul (Plamsur), que destinou recursos financeiros para projetos voltados ao desenvolvimento de plantas medicinais no Brasil, Paraguai, Uruguai e Argentina (MDA, 2007).

No 4 Seminário Estadual, realizado em 2002, as atenções voltavam-se para a efetivação e monitoramento da Política Intersetorial de Plantas Medicinais que começava a entrar em vigência. No mesmo ano, o Fórum pela Vida participou da criação de uma rede envolvendo países do Mercosul, chamada de Mercofito. A rede visava o debate sobre uso de fitoterápicos nos sistemas de saúde nos países membros, buscava promover o desenvolvimento de polos produtivos regionais pela incorporação de cultivos de plantas medicinais, procurava conscientizar a população sobre o uso racional das plantas medicinais e tentava criar uma farmacopeia do Mercosul. Sua criação incentivou a formação de uma rede de cooperação entre os países e suas entidades, sendo realizado, em 2002, o I Seminário Internacional de Medicamentos Fitoterápicos na cidade de Panambi (RS/Brasil). O segundo seminário foi em 2006, na cidade de Foz do Iguaçu (Tríplice Fronteira), e, em 2007, o terceiro se realizou em Buenos Aires (Argentina); o último encontro foi em 2012, na cidade de Porto Alegre (RS/Brasil).

Quando o Projeto Plantas Vivas chegou a sua quinta edição de Seminário Estadual, no ano de 2003, diversas conquistas já se somavam na trajetória de organização e mobilização. Na ocasião, foi elaborada uma nova Carta ao Rio Grande do Sul que, dentre as reivindicações, solicitava a continuidade da Política Intersetorial no RS, o apoio ao Seminário Nacional de Plantas Medicinais, Fitoterápicos e Assistência Farmacêutica (realizado pelo Ministério da Saúde em 2003) e a participação do Fórum pela Vida na I Conferência de Assistência Farmacêutica (CONY, 2004). O documento também pautava o apoio às iniciativas em todo o Brasil que visassem à construção de um novo projeto de desenvolvimento econômico e social, progresso, democracia e soberania nacional (CONY, 2004).

No 60 Seminário Estadual, realizado em 2004, o fórum decide por renovar os compromissos, dando continuidade à articulação estadual e solicitando ao governo federal a criação de uma comissão permanente interministerial para elaborar uma proposta de Política Nacional de Plantas Medicinais e Medicamentos Fitoterápicos, dentre outras solicitações. Já no 70 Seminário, ocorrido no ano de 2005, é realizado o resgate da trajetória histórica do Fórum pela Vida, e fica registrado, dentre outras coisas, o aumento das regionais, sendo, na ocasião, um total de dez: Sul, Centro-Oeste, Serra, Metropolitana, Missioneira, Vale do Taquari, Noroeste, Cruz Alta, Vale dos Sinos e Fronteira-Oeste.

No oitavo e último Seminário Estadual do Projeto Plantas Vivas, no ano de 2006, os desafios consistiam na vigilância (ou controle social) das iniciativas construídas pela organização e mobilização social, como a aprovação da legislação estadual e nacional para as plantas medicinais e fitoterápicos. Vale ressaltar que foram aprovadas, neste período, a Lei Estadual $n^{\circ}$ 12.560/2006 que cria a Política Intersetorial de Plantas Medicinais e de Medicamentos Fitoterápicos, a Política Nacional de Plantas Medicinais e Fitoterápicos (Decreto $n^{\circ} 5.813 / 2006$ ) e a Política Nacional de Práticas Integrativas e Complementares (Portaria $n^{\circ}$ 971/2006). O Projeto Plantas Vivas teve participação na construção das principais políticas e programas para as plantas medicinais e fitoterápicos, desempenhando uma ação política que incorpora noções de valores ambientais 
e sociais. O importante a destacar, aqui, é o espaço político aberto pelo Fórum ao criar condições para articulações sociais e políticas diferentes das formas convencionais de participação política (sindicatos e movimentos sociais caracteristicamente pautados pela "luta de classes"). Ainda que abrigando muitos agentes públicos com diferentes filiações institucionais, a ação do Fórum pode ser considerada relativamente autônoma, em especial pela capacidade de influenciar discursos e ações que contribuíram para a construção de legislações estadual e nacional, e da construção de outras organizações, como a Rede Fito/RS, Plamsur e Mercofito.

A participação de organizações não tradicionais no debate político, conforme abordado por Giddens (1996) e também por Beck (1997, 1999), traz alguns elementos interessantes para a compreensão desta trajetória do Fórum. Segundo Giddens (1996), as práticas sociais foram influenciadas pela globalização, alterando os hábitos da vida local, mas também gerando possibilidade de ampliação da reflexividade dos atores. Parece ser justamente o exemplo trazido pelo FPV, se considerar as motivações que levaram os atores à mobilização social, ou seja, diante da globalização o conhecimento perito, representado pela indústria farmacêutica, tornou acessível à população uma gama de medicamentos e tratamentos de saúde, considerado por muitos como um avanço na área da saúde. O conhecimento e práticas populares nesse processo, no entanto, sofreram questionamentos quanto a sua legitimidade, sendo, aos poucos, substituídos por conhecimentos "externos" à realidade local.

O colegiado do Fórum, entendendo estas problemáticas e as implicações de ambos os processos, passou a refletir e propôs a união entre os dois corpos de conhecimento - o científico e o popular -, por compreender que ambos possuem suas contribuições e um não deve se sobrepor ao outro. Na ordem social pós-tradicional, a decisão dos atores aparece relacionada à reflexão e ao conhecimento, ou seja, ao incorporar a reflexividade, atribuem-se novas responsabilidades, podendo ser interpretada como uma importante forma de ação política contemporânea.

Apesar dos avanços em termos de políticas específicas para as plantas medicinais e fitoterapia, a articulação estadual do Projeto Plantas Vivas foi interrompida juntamente com o oitavo seminário. Avaliou-se que isto aconteceu em razão das ações desmobilizadoras, considerando que gestões sucessivas no governo estadual não priorizaram a devida continuidade das políticas públicas. Também é perceptível que muito pouco das ações abrigadas pela política nacional teve maior impacto ou visibilidade no RS. Outra avaliação possível é de que, como o Fórum, como um espaço político bastante institucionalizado, se beneficiava do ambiente legislativo para realizar ações, com o final de mandatos da deputada estadual Jussara Cony não foram construídas novas alternativas para a continuação do Projeto Plantas Vivas.

Neste sentido, o emaranhado de atores e organizações também enfrentou contradições ante a diversidade de composição e a flutuação de participação dos distintos grupos e entidades, ainda que, em diversos momentos, tenham sido firmados compromissos formalizados. A ação mais direta do Fórum parece ter se constituído efetivamente no diálogo com o Estado, exigindo recursos e reclamando direitos, porém as pautas expõem sua heterogeneidade e parece ter havido dificuldade em renovar lideranças. 
O Fórum pela Vida ampliou, no entanto, relações na medida em que foi incorporando um número cada vez maior de associações, movimentos urbanos, indígenas, sindicatos, ONGs e outras organizações atuantes em áreas como saúde, gênero, educação, agricultura, meio ambiente e outras. As relações ampliaram-se porque representantes do Fórum foram trabalhando no sentido de aproximar-se a organizações de outros Estados brasileiros e países do Mercosul (Mercofito e Plamsur). Com isto, avalia-se que foram processos de intensa participação e articulação, que acabaram por deixar vários "frutos", um deles na Região Noroeste.

\section{FÓRUM PELA VIDA: A Experiência no Noroeste Gaúcho}

Como enfatizado anteriormente, o Fórum pela Vida na Região Noroeste foi o único núcleo que persistiu a partir da desmobilização estadual do Projeto Plantas Vivas. É importante frisar que a sua inserção no projeto ocorreu no ano de 2002, mas localmente o trabalho com plantas medicinais já vinha sendo realizado por meio de algumas iniciativas locais, como ações da extensão rural, das pastorais da saúde, grupo de muIheres ligadas a sindicato de trabalhadores rurais, dentre outros.

A constituição de um fórum de discussão sobre plantas medicinais, e que também reunisse as experiências locais, surgiu a partir de uma ideia lançada no 1 은 Seminário sobre Plantas Medicinais, realizado no Sindicato dos Trabalhadores Rurais de Santo Cristo no ano de 2001. Inspirado no Fórum Missioneiro, a ideia tomou força após a participação de alguns atores locais no 3 o Seminário Estadual do Projeto Plantas Vivas, que havia sido realizado em Porto Alegre. Localmente, a temática vinha sendo discutida, considerando que já emergiam algumas experiências, como o Programa de Saúde Alternativa em Santo Cristo, ${ }^{6}$ palestras em escolas, grupos de mulheres, exposição de plantas em feiras e eventos, oficinas em comunidades rurais, dias de campo, dentre outras.

Assim, a região constitui uma Comissão Intermunicipal de Plantas Medicinais e uma Coordenação Regional do Fórum pela Vida, aderindo à proposta estadual, em 2002, quando é realizado o 10 Fórum pela Vida no município de Santa Rosa. Os municípios que passaram a compor o Fórum são da região de abrangência do Corede Fronteira Noroeste e também da 14을 Coordenaria Regional de Saúde, sendo eles: Alecrim, Alegria, Boa Vista do Buricá, Campina das Missões, Cândido Godói, Doutor Maurício Cardoso, Giruá, Horizontina, Independência, Nova Candelária, Porto Lucena, Porto Mauá, Porto Vera Cruz, Santa Rosa, Santo Cristo, São José do Inhacorá, São Paulo das Missões, Senador Salgado Filho, Três de Maio, Tuparendi e Tucunduva.

O objetivo da criação do Fórum foi instituir um momento para que as pessoas na região pudessem trocar ideias e experiências, especialmente relacionadas à preservação, recuperação, valorização das plantas medicinais, além de pensarem juntas como construir propostas para um trabalho efetivo e articulado. Com o passar dos anos, as propostas transcenderam o evento e passaram a fazer parte das comunidades, mate-

\footnotetext{
${ }_{6}^{6}$ O Programa Saúde Alternativa é uma experiência iniciada pelo movimento de mulheres ligado ao Sindicato dos Trabalhadores Rurais, a qual resultou num espaço de atendimento para a população que busca curar ou prevenir doenças a partir de tratamentos naturais, principalmente com chás, reiki, massagens dentre outros. $\mathrm{O}$ espaço, atualmente, é gerido por três mulheres que se especializaram em tais conhecimentos e que realizam o atendimento para a comunidade.
} 
rializadas em hortos medicinais em propriedades voltadas à atividade leiteira a partir da cura de mastite por meio de homeopatia, por exemplo. De qualquer modo, o evento ainda ocorre anualmente e prevalece o rodízio entre os municípios da região, e o próximo fórum já é marcado no encerramento do evento em curso. Existe uma lista de municípios interessados em sediá-lo, demonstrando a importância do mesmo para as discussões sobre plantas medicinais e outros assuntos, como auto-organização comunitária, valorização do conhecimento popular, fomento à biodiversidade e trocas de mudas (Entrevista 1, março/2015). O Quadro 1 traz a evolução do número de participantes, que se constitui em informação interessante para delinear a dimensão dos eventos, mas, especialmente, a importância dada a ele, considerando que é significativa a participação das pessoas da região.

Quadro 1 - Evolução do número de participantes no Fórum pela Vida Fronteira Noroeste

\begin{tabular}{|l|c|c|}
\hline Município & Edição/Ano & No de Participantes \\
\hline Santa Rosa & $1^{\circ} / 2002$ & 980 \\
\hline Santo Cristo & $2^{\circ} / 2003$ & 360 \\
\hline Tucunduva & $3^{\circ} / 2004$ & 651 \\
\hline Campina das Missões & $4^{\circ} / 2005$ & 673 \\
\hline Alecrim & $5^{\circ} / 2006$ & 575 \\
\hline Três de Maio & $6^{\circ} / 2007$ & 734 \\
\hline Santa Rosa & $7^{\circ} / 2008$ & 478 \\
\hline Senador Salgado Filho & $8^{\circ} / 2009$ & 535 \\
\hline Cândido Godói & $9^{\circ} / 2010$ & 832 \\
\hline Porto Vera Cruz & $10^{\circ} / 2011$ & 473 \\
\hline Independência & $11^{\circ} / 2012$ & 580 \\
\hline Porto Mauá & $12^{\circ} / 2013$ & 870 \\
\hline Boa Vista do Buricá & $13^{\circ} / 2014$ & 620 \\
\hline Nova Candelária & $14 \% / 2015$ & 800 \\
\hline Tuparendi & $15^{\circ} \% / 2016$ & 900 \\
\hline Cândido Godói & $16^{\circ} / 2017$ & 1.000 \\
\hline
\end{tabular}

Fonte: Elaborado pelas autoras segundo dados da Emater (2018).

Dentre estes muitos participantes, indicados no quadro supra, encontravam-se agricultores familiares, extensionistas rurais, agentes de saúde, profissionais da saúde, agentes públicos de distintas organizações governamentais, pessoas ligadas aos movimentos sociais e sindicais, professores e estudantes de universidades, escolas técnicas e outras instituições de ensino, pesquisadores, pessoas ligadas a igrejas ou outras organizações religiosas, indígenas e suas representações, apenas para citar alguns. Em cada edição do Fórum uma comissão municipal é montada com a finalidade de organizar o evento, escolhendo a temática, os palestrantes, oficinas e apresentações artísticas que se tornaram marcas dos eventos. A comissão, meses antes do evento, reúne-se periodicamente envolvendo diversas entidades.

As impressões colhidas a partir das entrevistas permitem entender que a decisão sobre o município que sedia o Fórum, a composição da comissão organizadora e o tensionamento nas escolhas temáticas, acabam por fazer do próprio processo de organização do evento uma "arena". Embora esse espaço de disputa seja criado pelo encontro dos distintos atores "cara a cara", é preciso entender que, embora a noção de arena 
evoque a imagem de um campo de batalha demarcado, nem sempre as arenas são delimitadas, pois, muitas vezes, as disputas não ocorrem ali, mas invocam uma disputa de interesses, valores e competições sociais, podendo ocorrer em contextos institucionais externos e geograficamente distantes (LONG, 2007). Com isto, analisa-se que o processo que vem ocorrendo anualmente, no sentido de garantir infraestrutura e condições para o debate regional, tem sua ação ampliada pela criação de redes de atores que se mobilizam e fazem fluir ideias (e disputas), ampliando, então, a arena (no sentido de Long) a outros espaços e, especialmente, levando a discussão para o cotidiano, inclusive para o interior das diferentes organizações envolvidas.

A análise documental das programações dos eventos mostra as parcerias estabelecidas entre organizações presentes na região e que mais ou menos se repetem mesmo com as mudanças de local dos eventos. Dentre as organizações destacam-se: Emater, Sindicatos dos Trabalhadores Rurais, Movimento de Mulheres, Pastoral da Criança, Pastoral da Saúde, Igrejas, Clubes de Mães, Secretarias de Saúde dos municípios, Prefeituras, Câmaras de Vereadores e universidades da região. Os eventos, eventualmente, contaram também com apoiadores de setores públicos, que foram mobilizados dependendo de cada edição, sendo eles Assembleia Legislativa, Coordenadoria Regional de Agricultura, Coordenadoria Regional de Saúde, Coordenadoria Regional de Educação e Secretarias de Estado, como do Meio Ambiente e do Desenvolvimento Rural, além da Fundação Zoobotânica.

Para a realização dos eventos as Comissões têm autonomia para buscar apoio e patrocínios, o que mobiliza, muitas vezes, as redes individuais de contato, como no caso do $11^{\circ}$ Fórum, realizado no município de Independência, que contou com o apoio de uma Instituição Financeira Cooperativa (Sicredi), Cooperativa Agropecuária Alto Uruguai Ltda. (Cootrimaio) e uma agropecuária. ${ }^{7}$ Os apoios visaram a auxiliar a divulgação, além de terem consistido na doação de materiais e de mudas, patrocínio dos almoços, dentre outros.

Com o passar dos anos, os organizadores perceberam a ampliação do público participante, e outros municípios, de regiões próximas, começaram a manifestar interesse em sediar o Fórum. Desta forma, eles decidem criar um novo fórum para contemplar os municípios da região das Missões, ${ }^{8}$ sendo eles: Bossoroca, Caibaté, Cerro Largo, Dezesseis de Novembro, Entre-ljuís, Eugênio de Castro, Garruchos, Giruá, Guarani das Missões, Mato Queimado, Pirapó, Porto Xavier, Rolador, Roque Gonzales, Salvador das Missões, Santo Ângelo, Santo Antônio das Missões, São Luiz Gonzaga, São Miguel das Missões, São Nicolau, São Pedro do Butiá, Sete de Setembro, Ubiretama e Vitória das Missões.

O destaque mais significativo, aqui, é que passam a existir dois Fóruns pela Vida, um na região Fronteira Noroeste criado a partir do Projeto Plantas Vivas, e outro na região das Missões. O Fórum pela Vida Missões surge, então, no ano de 2013, com o envolvimento de diversos atores e organizações, seguindo a lógica organizativa da Região Fronteira Noroeste, ou seja, com a criação de uma Comissão Intermunicipal, busca de

\footnotetext{
${ }^{7}$ Estabelecimento comercial destinado para comercialização de insumos, mudas, pequenos animais, ferramentas e maquinários para atividade agrícola.

${ }^{8}$ Os municípios são organizados segundo o Corede Missões.
} 
apoiadores e formação de uma rede de atores e entidades. O Quadro 2 traz o número de participantes nas edições do evento, demonstrando, com bastante clareza, a motivação das pessoas em manter o debate ativo e a vitalidade das organizações no que respeita a sua capacidade de mobilização.

Quadro 2 - Trajetória do Fórum pela Vida Missões

\begin{tabular}{|l|c|c|}
\hline Município & Edição/Ano & $\mathbf{N}^{\circ}$ Participantes \\
\hline Caibaté & $1^{\circ} / 2013$ & 714 \\
\hline Sete de Setembro & $2^{\circ} / 2014$ & 1.280 \\
\hline Cerro Largo & $3 \% / 2015$ & 1.000 \\
\hline São Miguel das Missões & $4 \% / 2016$ & $1.000^{*}$ \\
\hline Santo Antônio das Missões & $5 \% / 2017$ & $1.000^{*}$ \\
\hline
\end{tabular}

* Número aproximado de participantes

Fonte: Elaborado pelas autoras segundo dados da Emater (2018).

Uma primeira avaliação possível é de que este segundo Fórum se trata de um desdobramento dos processos sociais em andamento desde os anos 90, mas, sobretudo, de uma ampliação das redes de atores possibilitada pela intensificação de capacidades de agência. Uma segunda ponderação é de que, como este "novo" fórum surge fora da atuação de um projeto estadual, ele representa que tem havido uma intensificação na densidade de experiências locais, uma transversalidade entre temáticas ligadas às plantas medicinais e uma ação política mais ampla (lutas da agricultura familiar, segurança e soberania alimentar) sem perder, contudo, o caráter da ação social local. Estes aspectos puderam ser apreendidos ao analisar as programações dos eventos ao longo dos anos, considerando novas relações que foram sendo estabelecidas.

Ainda, pode-se argumentar que não foi perdida a atualidade do debate sobre plantas medicinais, tampouco a necessidade da construção de espaços coletivos apesar de avanços identificados nas políticas públicas e eventuais ações de Estado na área. Além disto, percebe-se que as pessoas têm grande interesse pela troca de conhecimentos e aprendizagens, pois as plantas medicinais estão presentes na vida das comunidades rurais e na tradicionalidade envolvida no seu consumo. Em outras palavras, se politicamente o tema é atual e tensiona a política pública, reclamando a atenção das autoridades, ele também se expressa na colheita da marcela na Sexta-Feira Santa, na procura por benzedeiras, na busca por qualidade de vida, que passou a estar associada à diminuição do consumo de medicamentos convencionais e à substituição por "alternativos" (fitoterápicos, homeopatia, florais), considerando que todos estes elementos estão também presentes nos eventos. Ao analisar os documentos dos eventos, bem como das entrevistas com os envolvidos, pode-se perceber três grandes temáticas que, de certa forma, se repetem ao longo dos anos, que são políticas públicas, saúde humana e saúde animal.

A temática "política pública" fez parte de vários fóruns, o que é esperado na medida em que estava ligada inicialmente ao projeto estadual. Assim, diversos painéis foram realizados para discutir localmente a política estadual e nacional de plantas medicinais e medicamentos fitoterápicos. Nestes debates, a presença de representantes do poder legislativo e executivo foi frequente. Uma avaliação é de que estas oportunidades acabaram por aproximar as relações políticas do âmbito estadual e nacional com as lideran- 
ças locais. A aproximação provocou, para além do debate sobre as políticas, o estabelecimento de parcerias para criar leis e programas municipais de incentivo ao cultivo de plantas medicinais e instalação de polos regionais para produção de fitoterápicos.

A partir da análise das programações, percebemos que a maioria dos fóruns tinha como início as discussões referentes às políticas públicas para, em seguida, realizar debates temáticos, que ora dialogavam com a saúde humana, no seu sentido mais amplo, ora com a saúde animal, como fitoterapia na bovinocultura de leite (atividade bastante desenvolvida nas regiões). Após análise das programações e afirmações realizadas nas entrevistas, constatou-se que, com o passar das edições, o debate sobre as políticas aparentemente vai perdendo espaço para temas que estão mais relacionados com o cotidiano das pessoas. Em parte, este esfriamento do debate parece ter relação com certa decepção em relação aos programas governamentais específicos.

Desde as primeiras edições foram realizados debates que tinham como foco a saúde humana, estabelecendo uma clara relação com outro debate importante para a região - o uso de agrotóxicos na agricultura -, colocando em evidência as consequências tanto para os consumidores quanto para o ambiente. Estes temas são bons exemplos das transversalidades entre os assuntos e preocupações dos atores sociais que mobilizam os fóruns, neste caso as plantas medicinais e o uso dos fitoterápicos parecem servir de "ponte" ao permitir a relação entre o cuidado da saúde humana e a agricultura. Deste modo, painéis e oficinas realizados partiram, com muita frequência, da insistência no uso de manejos ecológicos para produção de alimentos, mas, principalmente, para produção das plantas medicinais consumidas, considerando que serão usadas em processos de cura e, em sua grande maioria, in natura.

Outras transversalidades podem ser percebidas na relação com as temáticas da saúde da mulher, da saúde do homem (especialmente trabalhando a prevenção), saúde do idoso, das terapias complementares, da ginástica laboral, da prevenção do câncer de pele, da humanização do trabalho e do combate à depressão, por exemplo pelo estímulo às discussões sobre autoestima, dentre outros assuntos. Os interlocutores da pesquisa reportam que há uma percepção crescente de problemáticas que provêm do cotidiano dos agricultores, como a exposição ao sol e o manuseio de agrotóxicos e a relação com a incidência de câncer, ou as dores musculares e as doenças produzidas pelo trabalho repetitivo. Isto permite analisar que da percepção ao compartilhamento público das preocupações há uma margem crescente da politização desses temas. Aqui, mais uma vez, se pode recorrer à noção de "subpolítica" (BECK, 1997), porém, reforçada por essa entrada pela experiência, pelo vivido e não apenas pelo discurso.

Um valor específico e objetivo dado à realização dos fóruns é seu caráter prático. Deste modo, as programações de praticamente todas as edições continham momentos que se pode chamar de facilitadores de trocas de conhecimentos e aprendizagem. É assim que as oficinas são consideradas a cereja do bolo, e elas versam sobre: produtos de higiene e limpeza; preparo de tinturas, essências, pomadas, xaropes caseiros; hidroterapia; homeopatia; plantas companheiras nas hortas domésticas; organização de hortos; controle ecológico de pragas nas hortas caseiras; plantio de plantas medicinais; cuida- 
dos com a alimentação e multimisturas; ${ }^{9}$ fitoterapia; confecção de travesseiros aromáticos (e outros artesanatos); aproveitamento integral dos alimentos, flores e plantas na alimentação, apenas para citar algumas. Esta característica formativa das oficinas tem uma estreita relação com o trabalho da Emater na região, considerando que as extensionistas sempre estiveram envolvidas muito de perto na organização dos fóruns, com maior ou menor apoio institucional, a depender das conjunturas internas.

Outro eixo relevante da existência dos fóruns é a circulação de materialidades. Em outras palavras, os eventos, ao proporcionarem encontros entre as pessoas, estendem os significados do debate político para o mundo do concreto. Em todos os eventos ocorrem exposição e distribuição de mudas e sementes crioulas, além de feiras de trocas de mudas entre os participantes. Os relatos dão conta da riqueza destes encontros não apenas pelas trocas em si, que são interessantes ao incrementarem diversidades nas propriedades, mas também pelo tornar públicos a importância e o valor de "coisas" antes vistas como imagens de atraso e até de vergonha, ou seja, os recursos disponíveis na propriedade, como os chás e demais plantas medicinais.

Em uma das entrevistas realizadas, uma das extensionistas relata que as coordenações municipais se preocupavam em demasia na organização de discussões, trazendo palestrantes de fora e colocando relevância em certos temas, mas o interesse maior e foco dos participantes sempre foram às oficinas. A interlocutora afirma que a aprendizagem, muitas vezes, é entendida como primordial para melhorar os cuidados da saúde da família, assim como é avaliada como potencial para a geração de renda, por exemplo, pela elaboração de produtos caseiros aprendidos nas oficinas, que podem vir a se tornar produtos para comercialização. Esta constatação levou os organizadores a ampliar o tempo das oficinas e reduzir as discussões, embora elas não tenham deixado de ser realizadas.

Vale ressaltar que, em duas edições, as discussões foram organizadas com centralidade em duas plantas medicinais específicas. Em 2005 a marcela (Achyrocline satureioides), aquela escolhida como símbolo do RS, e, em 2006, o alecrim (Rosmarinus officinalis), em especial porque o evento foi realizado no município de Alecrim. O caráter desses fóruns se deu de forma diferencial, pois as discussões realizadas giraram em torno das plantas, colocando em evidência as propriedades medicinais, incentivando o cultivo e o consumo. Estes aspectos reforçam a intersecção entre os discursos produzidos, as interfaces de conhecimentos e a relação com elementos materiais, neste caso as plantas em si.

Ainda cabe mencionar que o tema da saúde animal foi crescendo em importância. No ano de 2008 foi realizada uma oficina chamada qualidade do leite e plantas medicinais em animais. Já, a partir de 2009, o tema passou a ser tratado como foco principal nas discussões. Por exemplo, estampado no material de divulgação está "uma vaca e um tarro de leite". Neste mesmo ano houve palestras sobre a importância das plantas medicinais para o tratamento dos animais, como forma de incentivar a substituição de antibióticos pela fitoterapia e homeopatia.

${ }^{9}$ Trabalho contra desnutrição levado a cabo pelas Pastorais, conhecido no Brasil todo. Trata do aproveitamento de folhas verdes e outros produtos para o preparo da multimistura, uma espécie de complemento alimentar rico em minerais. 
Em uma das entrevistas, um extensionista (entrevista março/2015) explicou que, além de reduzir custos com medicamentos e antibióticos, a adoção de tratamentos alternativos recupera plantas e conhecimentos, além da autonomia dos produtores ante o cuidado da saúde animal. Uma das principais plantas recuperadas e incentivadas na fitoterapia é a cobrina (Tabernaemontana catharinensis), árvore nativa do Sul do Brasil, sendo encontrada também no Uruguai e Paraguai. Ela é considerada uma planta cicatrizante, anti-inflamatória e analgésica, sendo utilizada principalmente para prevenir a mastite e carrapatos nos bovinos. O extensionista conta, também, que se usa a planta em misturas como detergentes, desinfetantes e sabão para lavar os animais.

É importante registrar que a bovinocultura de leite é considerada uma das principais atividades produtivas na região, sendo desenvolvida principalmente pela agricultura familiar e que, nos últimos anos, vive "altos e baixos", em razão dos preços pagos aos produtores e a oligopolização das indústrias processadoras. Este aspecto ajuda a evidenciar as relações que vão sendo estabelecidas entre as problemáticas, pois, o debate "entra" pelas plantas e conhecimentos associados, mas vai sendo permeado por outras questões políticas, considerando que a defesa das pequenas produções de leite tem sido bandeira dos sindicatos da região. Este eixo da análise reforça a transversalidade das temáticas, mas, em especial, a complexidade de relações que se estabeleceram ao longo dos anos, mesclando aprendizagem, recuperação de plantas e conhecimentos, dinâmicas sociais que parecem apontar o Fórum pela Vida como parte de um processo de ampliação da "margem de manobra" dos atores.

As pessoas constroem pontes e gerenciam interfaces críticas que constituem intersecções entre seus diversos mundos de vida (ARCE; LONG, 1994). Assim, dar ênfase às oficinas não necessariamente retira o caráter político dos encontros, e muito menos das articulações entre os atores que não se restringem aos eventos em si. A ampliação de processos de aprendizagem faz parte ou incorpora múltiplos aspectos da vida social e dos processos cognitivos nela envolvidos (LONG; PLOEG, 1994, 2001). Sendo assim, as transversalidades de temas parecem fazer surgir também novas demandas (as oficinas práticas, por exemplo), de maneira a contribuir para a ampliação da capacidade de agência de todos os envolvidos nos processos.

\section{CONSIDERAÇÕES FINAIS}

A identificação das dinâmicas dos atores sociais relacionadas às plantas medicinais no contexto da Região Noroeste do Rio Grande do Sul, foi dando sequência ao próprio debate sobre o desenvolvimento. A modernização da agricultura causou uma série de transformações, entre as quais a homogeneização das práticas pela adoção de pacotes tecnológicos apregoados pelo modelo industrial figura-se como a principal. A chamada "agricultura dos agricultores" é transformada, causando desconexões com a terra, a natureza e a ecologia, tornando-a controlada e artificializada. Apesar, no entanto, dos esforços homogeneizantes da modernização da agricultura, o espaço rural constitui-se como um local heterogêneo.

Em outras palavras, ao seguirem-se as práticas sociais foram se evidenciando as formas heterogêneas no rural e possibilitou-se repensar os processos de desenvolvimento, uma vez que os atores sociais possuem agência e realizam manobras para garantir seus mundos de vida. Esse aspecto fica evidente com o Projeto Plantas Vivas, 
que buscava reverter a lógica e a dependência de medicamentos industriais, quando se passou a discutir e a se construírem políticas públicas voltadas ao reconhecimento das práticas e saberes populares, como a Política Intersetorial de Plantas Medicinais e de Medicamentos Fitoterápicos no Estado do Rio Grande do Sul, por exemplo.

Outra evidência das formas heterogêneas do rural é representada pela resistência do Fórum pela Vida na Região Noroeste, que, apesar da desmobilização estadual, a partir do ano de 2006, continuou atuando e fortalecendo as experiências locais de trabalho com plantas medicinais, materializadas em hortos medicinais, na troca de mudas, promovendo o fomento à biodiversidade, auto-organização comunitária e valorização do conhecimento popular, numa região caracterizada pela predominância de monoculturas. Ao serem seguidas as práticas sociais, foi possível identificar o trabalho local com plantas medicinais a partir do acompanhamento dos atores sociais e protagonistas desse processo.

Cabe ressaltar que o Fórum pela Vida é consequência da articulação estadual e foi iniciado, com o Projeto Plantas Vivas, ainda no final dos anos 90. A existência de trabalho local com plantas medicinais, entretanto, é anterior ao próprio processo de mobilização social, sendo identificada como um dos fatores que fortaleceu o Fórum regional, único que persistiu ao longo dos anos. Atualmente, o Fórum pela Vida na Região Noroeste (eventos ocorridos nos municípios da Fronteira Noroeste e Missões) identifica-se como celebração do conhecimento, bem como do fortalecimento das experiências de trabalho com plantas medicinais.

Nesse sentido, a ação coletiva nos processos organizativos carrega preocupações quanto à manutenção da biodiversidade de plantas medicinais, uma vez que incentiva o resgate e o cultivo das plantas, valoriza conhecimentos e práticas tradicionais (papel desempenhado principalmente pelo Fórum pela Vida) e incentiva a busca por qualidade de vida e prevenção de doenças, podendo ser identificada nas várias palestras do Fórum.

\section{REFERÊNCIAS}

ARCE, A.; LONG, N. Re-positioning knowledge in the study of rural development. In: SYMES, D.; JANSEN, A. J. (eds.). Agricultural restructuring and rural change in Europe. Wageningen: Agricultural University Wageningen, 1994. p. 75-86.

BECK, U. A reinvenção da política: rumo a uma teoria da modernização reflexiva. In: BECK, U.; GIDDENS, A.; LASH, S. Modernização reflexiva: política, tradição e estética na ordem social moderna. São Paulo: Unesp, 1997.

BECK, U. World risk society. Cambridge: Polity Press, 1999.

BENETTI, M. D. Reestruturação das indústrias de suprimentos agrícolas no Brasil, nos anos 90: concentração e desnacionalização. FEE, Porto Alegre, v. 30, n. 1, p. 137-166, jun. 2002.

BRUMER, A.; ROSENFIELD, C. L.; HOLZMANN, L.; SANTOS, T. S. dos. A elaboração de projetos de pesquisa em Ciências Sociais. In: PINTO, C. R. J.; GUAZZELLI, C. A. B. (org.). Ciências humanas: pesquisa e método. Porto Alegre: Ed. UFRGS, 2008. p. 125-146.

CHARÃO-MARQUES, F. Velhos conhecimentos, novos desenvolvimentos: transições no regime sóciotecnico da agricultura. A produção de novidades entre agricultores produtores de plantas medicinais no Sul

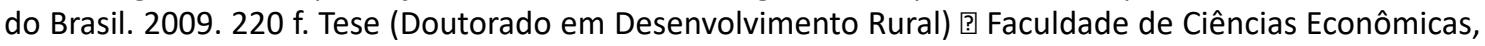
Universidade Federal do Rio Grande do Sul, Porto Alegre, 2009.

CONY, J. Projeto plantas vivas. Porto Alegre: Assembléia Legislativa do Rio Grande do Sul, 2004. p. 59.

GIDDENS, A. A vida em uma sociedade pós-tradicional. In: BECK, U.; GIDDENS, A.; LASH, S. (org.). Modernização reflexiva: política, tradição estética na ordem social moderna. São Paulo: Unesp, 1997. p. 73-133. GIDDENS, A. Para além da esquerda e da direita. São Paulo: Unesp, 1996. 
LONG, N. Development sociology: actor perspectives. London: Routledge, 2001. 293 p.

LONG, N. Sociología del desarrollo: una perspectiva centrada en el actor. San Luis de Potosí, México: El Colegio de San Luís, 2007. 499p.

LONG, N.; PLOEG, J. D. Van Der. Heterogeneidade, ator e estrutura: para a reconstituição do conceito de estrutura. In: SCHNEIDER, S.; GAZOLLA, M. (org.). Os atores do desenvolvimento rural. Porto Alegre. Ed. UFRGS. 2001. p. 323.

LONG, N.; PLOEG, J. D. Van Der. Heterogeneity, actor and structure: towards a reconstitution of the concept structure. In: BOOTH, D. Rethinking Social Development: theory, research and practice. Lond: Longman Scientific \& Technical, 1994. p. 62-89.

MDA. Ministério do Desenvolvimento Agrário. Comitê gestor brasileiro do Plamsur planeja ações para 2007. 2007. Disponível em: http://www.mda.gov.br/sitemda/noticias/comit\%C3\%AA-gestor-brasileiro-do-plamsur-planeja-a\%C3\%A7\%C3\%B5es-para-2007. Acesso em: 23 jun. 2015.

SECRETARIA DE SAÚDE. 2012. Disponível em: http://portalarquivos.saude.gov.br/images/pdf/2014/ maio/12/apresentacao-apl-rs-2012.pdf. Acesso em: 12 mar. 2018. 